Eurasian Journal of Business and Economics, 13(25), 75-89, (2020).

\title{
The Colour Red for Emotion in Cross-Cultural E-Commerce
}

\author{
Peter BROEDER ${ }^{*}$, Nienke WILDEMAN ${ }^{* *}$
}

Received: March 3, 2020

Revised: April 20, 2020

Accepted: April 30, 2020.

\begin{abstract}
Web stores tend to differentiate themselves from competitors by relying on hedonic aspects, such as colour. This study focusses on web store colour and emotions in the online shopping process. Preferences of Western and Asian consumers are compared when exposed to a web store with specific colour values of red. This was done in the context of an online booking web store for hotels. An online experimental survey was conducted with two conditions, viz., dark red and light red. A total of 220 participants (130 Dutch and 90 Vietnamese) completed the questionnaire. Contrary to expectation, the results showed no direct effect of colour: the light red web store did not induce the highest booking intentions, though an indirect colour effect was found through the pleasure emotion. The light red web store induced more pleasure, which in turn induced higher booking intentions. Cultural differences (indulgent vs. restricted), influenced the relationship between colour and the arousal emotion. Participants from the more indulgent culture were more induced by the light colour web store.
\end{abstract}

Keywords: Consumer behaviour, colour, cross-cultural, e-commerce, emotion.

JEL Code Classification: M31, M37

UDC: 339.138

DOI: https://doi.org/10.17015/ejbe.2020.025.05.

\footnotetext{
* Corresponding author, Department of Communication and Cognition, Tilburg University, Tilburg, the Netherlands. E-mail: peter@broeder.com

** Tilburg University, Tilburg, the Netherlands. E-mail: nienkewildeman@hotmail.com

Copyright (C), 2020 Ala-Too International University.
} 


\section{Introduction}

For consumers, instrumental qualities of shopping (e.g., ease and broader selection) are important reasons for purchasing online (Mathwick, Malhotra, \& Rigdon, 2001). With the majority of web stores offering these instrumental qualities equally, hedonic aspects acquire importance in the online buying process (Francis, 2009). Web stores need to differentiate themselves from competitors by relying on the hedonic store atmospherics (Eroglu, Machleit, \& Davis, 2003). An online environment that evokes a positive emotional state in consumers, enhances their purchase intentions (Mazaheri, Richard, \& Laroche, 2011). Colour is especially of importance when forming an attitude-based purchase intention. Morton (2009) noted that $80 \%$ of what is assimilated through senses is visual, and about $80 \%$ of what we think of an environment is based on colour. Gorn, Chattopadhyay, Tracy, and Dahl (2004) showed that the background colour is of great importance from a marketing perspective and influences the buyers' perception of a web store. Hall and Hanna (2004) and Pelet and Papadopoulou (2012) additionally found that purchase intention increases in an online context, when the right colour was chosen. However, Pelet (2015) acknowledged that the strategic use of colour to influence emotions and behaviour is still an unresolved issue. The primary colours are yellow, blue, and red (Fraser \& Banks, 2004). Broeder and Scherp (2017) addressed colour preferences and effects in an online buying environment and found that colour does indeed influence the purchase intentions in an online environment. Yellow was the most persuasive colour. The premise for blue, as the most trust-inducing colour was investigated in a follow-up study by Broeder and Snijder (2019). They recommended the use of dark blue colour schemes in online (shopping) environments. The present study investigates the premise of Broeder and Scherp (2017) that red is the most emotion-inducing colour. Western and Asian cultures are taken into account, since it is expected that Asian cultures show less emotions, and Western cultures, more emotions. Hence, the research question of this study is as follows: What is the impact of emotion, caused by the influence of different shades of red (i.e., lighter or darker) in online environments, on behavioural intentions, differentiated by culture?

\section{Hypothesis Formation}

\subsection{Differentiations of Colour}

Although most people take it for granted, colour is a major cue when perceiving an object in the outside world. While we are unaware of the process of how colours are perceived by humans, our brain and eyes work in tandem to show us the colours around us. Colour is nothing more than light (Fraser \& Banks, 2004). Carried on different wavelengths, our eyes absorb the light and our brain converts it to the colours we see. Physically, based on these wavelengths, colours are decomposed on a spectrum of six. The long wavelength 'warm' colours are red, orange, and yellow. The short wavelength colours are the 'cold' colours such as green, blue, and violet (Singh, 2006). Clarke and Costall (2008) showed that cold colours are perceived as 
cool, comfortable, relaxing, peaceful, and calming in general. Additionally, these colours have the potential to decrease anxiety levels. In contrast, warm colours are considered more arousing. Fraser and Banks (2004) and Gorn et al. (2004) found that in particular, the colour red is linked to excitement, activity, strength, and stimulation. This colour can stimulate human feelings and activate people. More specifically, several studies confirmed that light red colours (high value hues) were perceived as more effective than dark red colours (e.g., Clarke \& Costall, 2008; Sherman \& Clore, 2009). In an online environment, differences in red colour associations might have a direct effect on the (intended) consuming behaviour. For the present, the following hypothesis is formulated:

H1: An online environment yields higher behavioural intentions with light red than dark red.

H2: An online environment yields higher emotion with light red than dark red.

\subsection{Differentiations of Emotions}

Emotional responses play a major role in an impression being formed. The colour that consumers perceive may alter their emotions, resulting in different attitudes towards the same object. Mehrabian and Russel (1974) proposed three kinds of user emotions: pleasure (P), arousal (A), and dominance (D). These so-called PAD descriptors have been widely used to capture consumers' emotional responses to environmental stimuli.

The first PAD descriptor, pleasure, is defined as the degree to which one feels good, joyful, happy, or satisfied in any situation (Mazaheri, Richard, \& Laroche, 2011). In online contexts, pleasure is an indicator of the web store's "likeability" (Poels \& Dewitte, 2008). Thus, if users feel pleasurable when they are shopping in a store, they will enjoy exploring it, and will exhibit purchase intention (Vieira, 2013). In addition, Gorn et al. (1997) found that high value colours produce greater feelings of relaxation and greater liking for the brand of the product. For pleasure, light shades of red are recommended. Hence, the following hypothesis is proposed:

H3: An online environment yields higher pleasure with light red than dark red.

The second PAD descriptor, arousal, indicates the degree to which one feels stimulated, active, or alert (Mazaheri, Richard, \& Laroche, 2011). In online contexts, arousal is an indicator of the web store's "motivational power" (Poels \& Dewitte, 2008). Several empirical studies showed that pleasure and arousal both have a positive effect on shopping behaviour, such as unplanned purchase, time spent on the web site, and overall satisfaction (Eroglu et al., 2003; Mummalaneni, 2005; Koo \& Ju, 2010). Interestingly, Lee and Lee (2006) found that reducing the negative effects of arousal also has a positive effect on purchase intentions. In addition, they found that a lighter red colour toned down associations of aggression and active feelings, compared to a darker shade of red. Hence, the following hypothesis is formulated: 
H4: An online environment yields lower arousal with light red than dark red.

The third PAD descriptor, dominance, is defined as the degree to which one feels unrestricted or free to act, controlling, influential, or autonomous (Mazaheri, Richard, \& Laroche, 2011). Often, studies do not include the emotion dominance, since most of the variants are explained by pleasure and arousal. However, Weathers, Subhash, and Wood (2007) and Hsieh, Chiu, Tang, and Lee (2018) found that the higher the perceived control by consumers, the higher the customer's satisfaction and purchase intentions. Consumers prefer to be able to control and have influence over the interaction process online. When they feel to be in control of the process online instead of the organisation (web store) itself, a greater sense of freedom and satisfaction is reached. This is in line with the Reactance Theory (Clee \& Wicklund, 1980), which proposes that people react to threats strongly, when their freedom of choice is taken away or reduced. People prefer autonomy in the process and prefer to make their own decisions without being pressured. Dominance might be perceived as a negative emotion by individuals and has the potential to eventually lead to anger. Van der Westhuizen and Solms (2015) showed a positive association between anger and dominance. Negative emotions or words are coupled with dark colour variations (Sherman \& Clore, 2009). When a negative emotion is coupled with a light colour, a mismatch occurs. The brightness of an object should produce facilitation or interference, depending on the valence (good vs. bad) of the word in question (Meier, Robinson, \& Clore, 2004). Perceived as a negative emotion, dominance would be coupled with a dark shaded colour. Hence, for dominance, the following hypothesis is proposed, that contrasts with the hypotheses for pleasure and arousal:

H5: An online environment yields higher dominance with dark red than light red.

\subsection{Cultural Differentiations}

An interesting cultural difference in relation to colour and emotion is the degree of indulgence. This refers to the extent to which people try to control their desires and impulses, based on the way they were raised. Relatively weak control is called "indulgence" and relatively strong control is called "restraint". Consumers can make indulgent choices across different consumption domains, such as travel and clothing. Further, although they indulge by purchasing expensive items or experiences, such as a holiday, indulging can happen also in relatively smaller but more common ways, such as buying a branded product. Any of these options could be considered an indulgence, if the consumer considers the choice as a treat (Cavanaugh, 2014). In an online context, indulgent consumption is also possible. Not only by the purchase of products online, but also store atmospherics adding hedonic aspects (such as colours or pictures) help to create an indulgent environment (Overby \& Lee, 2006). Hedonic consumption and thus being indulgent, are associated with guilt feelings (Okada, 2005; Basaran \& Buyukyilmaz, 2015). In an indulgent environment, consumers need to justify such consumption by emphasising the utilitarian aspects of their purchase. In individualistic cultures, decisions are based on individual preferences (Triandis \& 
Gelfand, 1998). This indicates that when individuals from indulgent, individualistic cultures can justify their consumption to themselves and prefer the product, they will purchase it. In restrained cultures, people are less likely to remember positive emotions, and have less control over their personal lives (Lu, Pattnaik, Xiao, \& Voola, 2017). Thus, indulgent countries tend to spend more, since they can justify purchases to themselves and only their individual preference counts. Consumers in restrained cultures cannot justify this to themselves and therefore demonstrate need-based purchase behaviour. Colour associations are expected to be less influential over consumer behaviour in restricted cultures, as consumers are expected to buy only products that are needed and will not be tempted to purchase indulgently. This leads to the following hypothesis:

H6: Culture influences the relationship among colour, emotions and behavioural intentions, such that a stronger, positive relationship exists for indulgent cultures than for restricted cultures.

\section{Method}

In the present study, an online survey was conducted with a $2 \times 2$ factorial design. The independent variables were culture (Dutch, Vietnamese), colour (light red, dark red), and emotion (pleasure, arousal, dominance). The dependent variable was booking intention (of an accommodation). In the conceptual model, emotion and culture were expected to influence the relationship between colour and booking intention.

\subsection{Sample}

Totally, 220 people completed an online survey. Their cultural background was ascertained through self-identification ("To what ethnic group do you belong? Dutch/Vietnamese"). There were 130 Dutch participants (all born in the Netherlands) and 90 Vietnamese participants (all born in Vietnam, 49\% living in Vietnam). The sample consisted of 86 men (39\%) and 134 women (61\%). Mean age was 28.37 years (age range 18-66 years). According to Hofstede (2019), Vietnam is a low indulgence culture (score 35 on a $0-100$ scale), while the Netherlands is a high indulgence culture (score 68).

\subsection{Online Environment}

The participants were presented with an accommodation offer (see Figure 1). They were randomly assigned to one of the two conditions with a different colour background: light valued red (RGB code $=$ \#FF7F7F) or dark valued red (RGB code = \#7F000). The images were based on the original Airbnb way of display. Some elements were deleted for their potentially confounding effect: i.e., the price per night, the rating and, the location (in both the search field and the description of the accommodation). All elements indicating an Airbnb environment were also deleted to avoid participants being influenced by the reputation of Airbnb. 


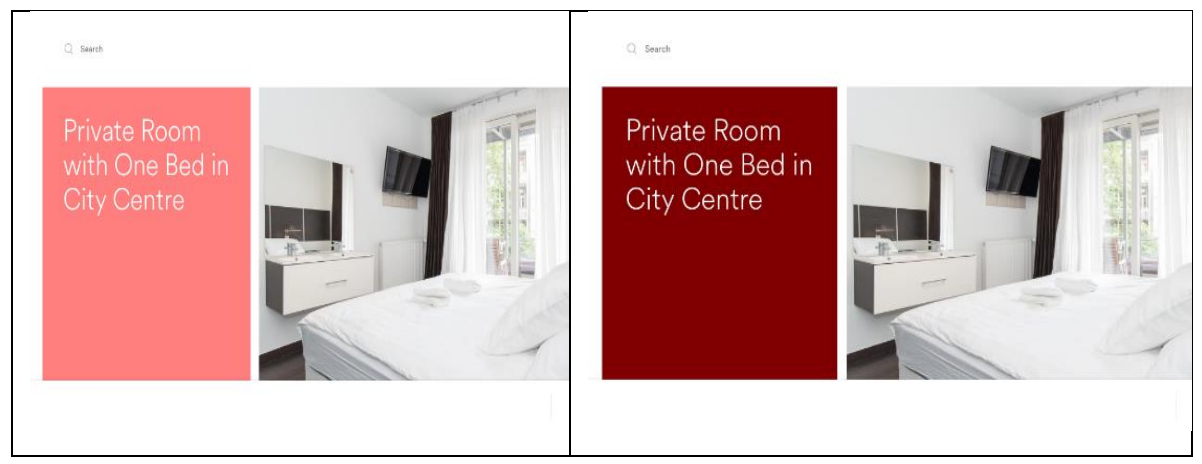

Figure 1. Accommodation Offer with a Light Red (left) and Dark Red (right) Environment

\subsection{Questionnaire}

The respondents were instructed to imagine a scenario in which "you are going on a city trip by yourself, you want to book a room". Then they were shown the accommodation offer and asked some questions. The Appendix gives all the items that were used in the scales of the questionnaire.

Booking intention was measured with one statement ("I would like to book this room"). Answers were given on a 5-point Likert scale $(M=3.91, S D=0.82)$. The emotion scale was adapted from Mehrabian and Russell (1974). The question "How does this colour makes you feel?" was answered on a 5-point-scale with nine contrasting adjective pairs in total: for pleasure ("annoyed/pleased", "(un)happy", "(un)satisfied", and "despairing/hopeful", $M=2.43, S D=0.71$ ), for arousal ("relaxed/stimulated", "calm/excited", "sleepy/wide-awake", and "(un)aroused", $M$ $=2.98, S D=0.75$ ), and for dominance ("in control/cared for", "controlling/ controlled", "dominant/ submissive", "influential/ influenced", $M=2.88, S D=0.61$ ). The degree of indulgence was measured with seven statements adapted from Sharma, Sivakumaran, and Marshall (2011) (e.g., "I enjoy spending money, I am a careful thinker"). Answers were given on a 5-point Likert scale $(M=3.52, S D=0.52)$. Online booking experience was addressed with two statements (e.g., "I am familiar with booking accommodation online") and a 5-point Likert scale ( $M=3.91, S D=$ 0.82 ). One question checked whether the respondents could remember the predominant colour used in the depicted online environment. Lastly, respondents were also presented with five coloured squares (light blue, dark blue, grey, light red, and dark red) and asked which colour they associated the most with emotion.

\section{Results}

\subsection{Manipulation Check}

The group of participants that associated emotion with specific colours did not differ by condition, $\mathrm{x}^{2}(4,215)=6.930, p=0.139$. Overall, in both conditions, the colour 
(light) red was associated the most with emotion. Grey was indicated the least emotional colour (see Table 1). So, in line with what was hypothesised, light red was associated more with emotion compared to dark red.

\section{Table 1. Reported Colours Associations with Emotion per Condition}

\begin{tabular}{lcc}
\hline This colour I associate the most & Light red condition & Dark red condition \\
with emotion ... & $(\mathrm{n}=112)$ & $(\mathrm{n}=103)$ \\
\hline Light red & $47(42 \%)$ & $42(41 \%)$ \\
Dark red & $43(38 \%)$ & $32(31 \%)$ \\
Grey & $6(5 \%)$ & $2(2 \%)$ \\
Dark blue & $2(2 \%)$ & $6(6 \%)$ \\
Light blue & $14(13 \%)$ & $21(20 \%)$ \\
\hline
\end{tabular}

Table 2 shows the cultural differences between the two groups in the sample of this study. On an average, the Dutch participants were less indulgent than the Vietnamese. However, the latter scored higher on prudence (Mdiff $=0.31$, BCa 95\% $\mathrm{Cl}[-0.49,-0.13], t(218)=-3.414, p=.001)$, effect size of $d=0.47)$ and uncertainty avoidance (Mdiff $=0.35$, BCa 95\% Cl $[-0.53,-0.18], t(206)=-3.978, p<.001$ ), effect size of $d=58$ ). This cultural comparison implied that the assumed differences between the Dutch and Vietnamese groups were confirmed for prudence. On an average, the Vietnamese participants reported less familiarity and experience with booking accommodations online than the Dutch. This difference, Mdiff $=0.26$, was significant, $(t(213)=2.39, p=.018, \mathrm{BCa} 95 \% \mathrm{Cl}[0.05,0.49])$ and represented a medium effect of $d=0.32$.

Table 2. Cultural Differences between the Dutch and Vietnamese groups (Means 5-point-scale; $\min .=1, \max .=5$; with standard deviations)

\begin{tabular}{lcc}
\hline & Dutch $(\mathrm{n}=130)$ & Vietnamese $(\mathrm{n}=90)$ \\
\hline Indulgence & $3.53(0.68)$ & $3.51(0.70)$ \\
Prudence & $3.38(0.69)$ & $3.69(0.63)$ \\
Experience & $4.02(0.74)$ & $3.76(0.89)$ \\
\hline
\end{tabular}

\subsection{Culture and Colour}

A two-way between-groups multivariate analysis of variance was performed to investigate cultural differences in colour-related emotions. Three dependent variables were used: pleasure, arousal, and dominance. The independent variables were culture and colour. For colour as the predictor, the difference between dark red and light red on the combined dependent variables (i.e., emotion) reached significance, $F(3,214)=2.56, p=.056$, Wilks' Lambda $=0.96$. When the results for the dependent variables were considered separately, only for pleasure a colourrelated difference was found, $F(1,218)=4.49, p=.035$, and represented a small effect of partial eta squared $=.020$. The relationships between the two values of red for each of the PAD descriptors are shown in Figure 2. 


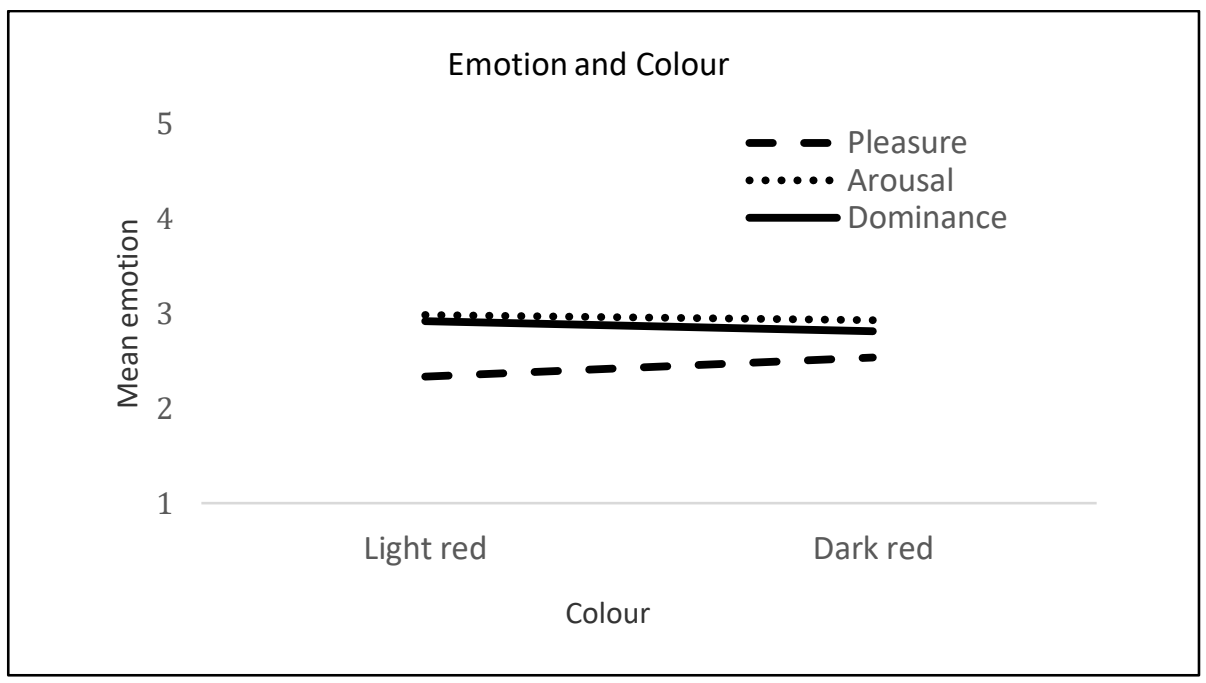

Figure 2. Relationship between the PAD Descriptors and Colour (Means 5-point-scale; $\min .=1$, $\max .=5$ )

An inspection of the mean scores indicated that for the colour dark red slightly higher levels of pleasure were reported $(M=2.56, S D=0.69)$ than for the colour light red $(M=2.32, S D=0.70)$. This finding is in contrast with what was hypothesised earlier that the higher values of red (i.e., light red) would evoke more emotion (Hypothesis 2) and more pleasure (Hypothesis 3).

For culture as the predictor, there was no significant difference between the Dutch and Vietnamese participants on the combined dependent variable emotion, $F(3$, 214) $=2.35, p=.081$, Wilks' Lambda $=0.70$. When the results for the dependent variables were considered separately, for arousal, a culture-related difference was found, $F(1,218)=6.40, p=.012$, and represented a small effect of partial eta squared $=.029$. The relationships between the two cultural groups for each of the PAD descriptors are shown in Figure 3.

An inspection of the mean scores indicated that the Dutch participants reported slightly higher levels of arousal $(M=3.09, S D=0.69)$ than the Vietnamese participants $(M=2.83, S D=0.82)$. This finding (partly) supports what was hypothesised earlier, that culture influences differently the relationship between colour and emotion (Hypothesis 6). 


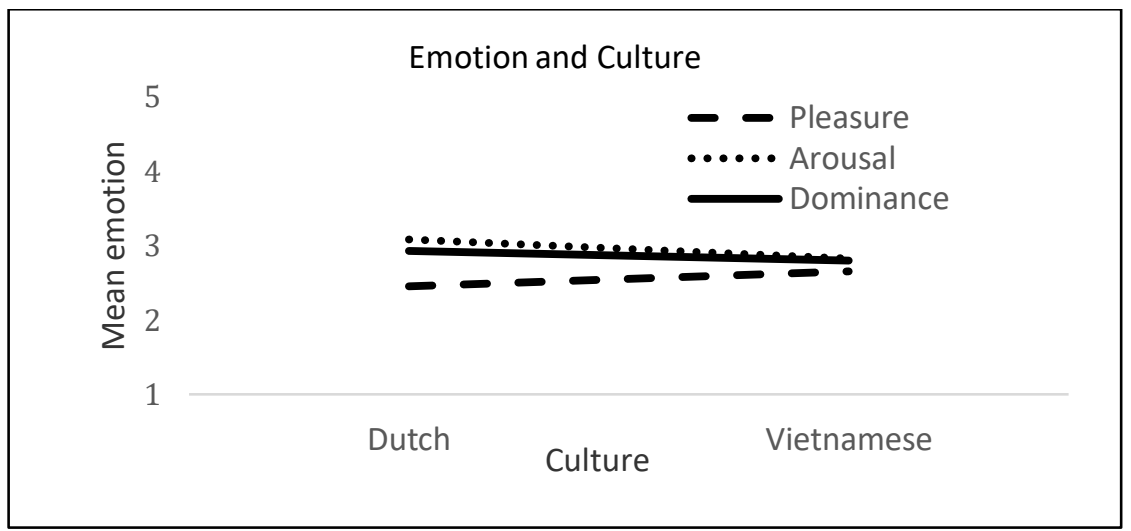

Figure 3. Relationship between the PAD Descriptors and Culture (Means 5-point-scale; $\min .=1, \max .=5$ )

\subsection{Booking Intentions}

To examine whether culture interacts with colour in predicting booking intentions, a moderation analysis was conducted, using the PROCESS procedures (model 1) developed by Hayes (2018). Culture was entered as an independent variable, booking intention as the dependent variable, and colour as the moderator. The outcome of the regression model is presented in Table 3.

Table 3. Linear Model of Predictors of the Change in Booking Intention

\begin{tabular}{lrccc}
\hline & $b[\mathrm{BCa} 95 \% \mathrm{Cl}]$ & $\mathrm{SE}$ & $t$ & $p$ \\
\hline Constant & $3.92[3.81,4.02]$ & 0.06 & 73.04 & $<.001$ \\
Colour (centred) & $-0.49[-0.71,-0.27]$ & 0.11 & -4.45 & $<.001$ \\
Culture (centred) & $0.02[-0.19,0,23]$ & 0.11 & 0.20 & .839 \\
Culture x Colour & $-0.05[-0.37,0.47]$ & 0.21 & 1.04 & .801 \\
\hline
\end{tabular}

Note: 95\% Bias Corrected and Accelerated Confidence Intervals Reported in Brackets. Confidence Intervals and Standard Errors based on 5000 Bootstrap Samples

The overall model was significant, $R^{2}=0.09, F(3,216)=2.59 p<.001$. There was a main effect of colour on booking intention. This supports Hypothesis 1. The effect of culture was not significant. Additionally, the results showed no significant interaction effect, indicating that the relationship between culture and booking intention is not moderated by emotion. This means that influence of culture is not supported (Hypothesis 6). The average booking intentions per colour and per culture are plotted in Figure 4. 


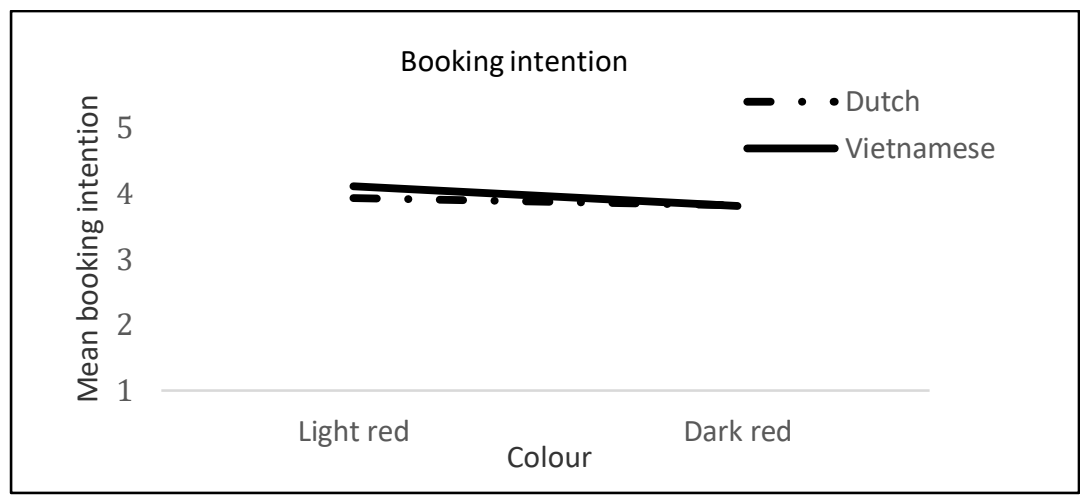

Figure 4. Relationship between Light and Dark Red, and Booking Intentions per Culture

\subsection{Emotion}

To further examine whether booking intentions can be explained by differences in colour and emotion, a mediation analysis was performed using PROCESS procedures (model 4) developed by Hayes (2018). In this analysis, colour was entered as a predictor for booking intention. Pleasure, arousal and dominance were entered as mediators.

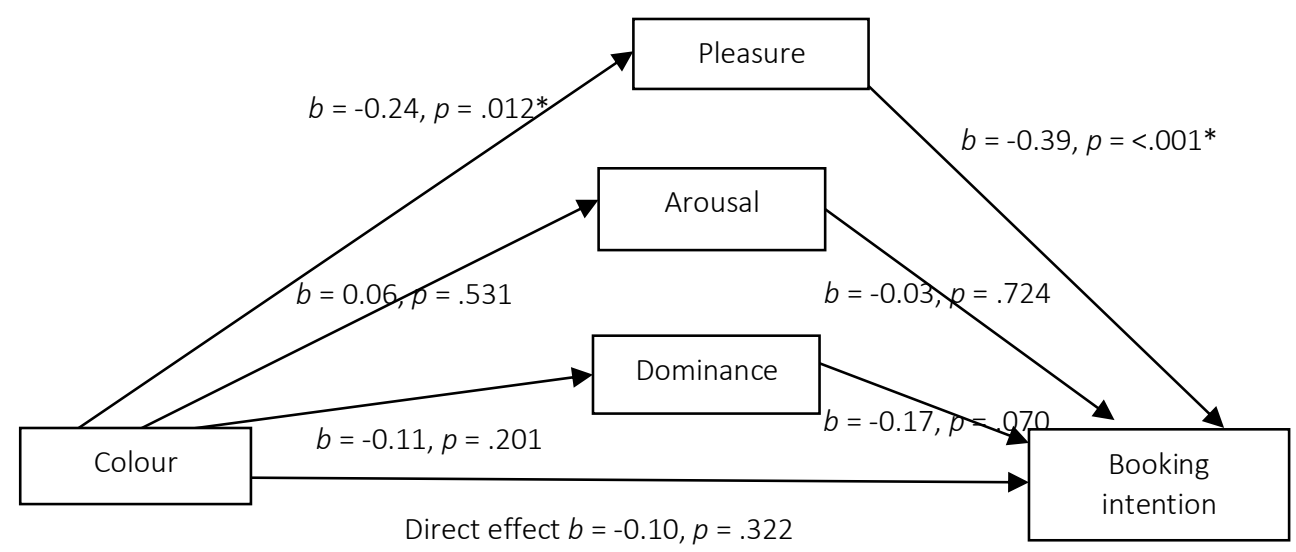

Indirect effect $b=-0.76,95 \% \mathrm{BCa} \mathrm{Cl}[-0.01,0.18]$

\section{Figure 5. Model of Colour as a Predictor of Booking Intention, Mediated by Pleasure, Arousal and Dominance}

Figure 5 shows that in the conceptual model the total standardised indirect effect was not significant $(b=-0.76,95 \% \mathrm{BCa} \mathrm{Cl}[-0.01,0.18])$. This was tested using bootstrapping procedures (5000 samples). Only for pleasure, the standardised regression coefficient between colour and pleasure was statistically significant, as was the standardised regression coefficient between pleasure and booking 
intention. Additionally, colour was found to negatively contribute to pleasure, and pleasure was found to negatively contribute to booking intention.

\section{Conclusions}

This study aimed to identify the role of emotion in the influence of colour on the online behavioural intentions of consumers. This was done in the context of an online booking web site for hotels. Additionally, possible differences between indulgent and restricted cultures in the influence of colour on online booking intentions were examined. The background hue of an advertisement and web store in an online environment is of great importance from a marketing angle, since it influences one's perspective online. It was expected that displaying a higher value red in an online environment would result in greater booking intentions, compared to a lower value of red. Dark red elicited indeed the lowest booking intentions, as expected.

The second set of hypotheses was set to identify the relationship between colour and emotions. It was found that for an online environment, displaying a high value red indeed induced a higher level of pleasure, compared to an online environment displaying a low value red. However, for an online environment displaying a lighter, higher value of red did not result in a higher level of arousal and dominance, compared to an online environment displaying a darker, low value red.

The final hypothesis proposed that culture moderates the relationship between the values of red displayed in an online environment and booking intentions. It was indeed found that Vietnamese buyers had a higher level of prudence, indicating that they were more cautious when purchasing. The level of indulgence did not differ significantly between Dutch and Vietnamese buyers, indicating that both cultures equally buy things for pleasure and for display of wealth. No interaction effect was found between the values and cultural background, indicating that cultural background does not play a moderating role.

\section{Limitations and Further Research}

Whilst this study provided interesting new knowledge, some limitations should be mentioned as well, since these may serve as interesting new topics for further research. One of the limitations expected to account for the outcomes, is the measurement of the cultural background of the participants. Whilst this study focused on the cultural background the participants identified with, the country of residence and the country of birth were not taken into account to identify one's culture. Especially the participants of Vietnamese origin were often living abroad, resulting in almost half the Vietnamese respondents currently living in another country. Since it is not known for how long the participants were living abroad, the possibility of fading of cultural practices should not be ignored. Future research should take this into account and examine whether there is indeed a difference between the cultural practices of a group living abroad or living in the country of 
their birth (see e.g., Bui, 2015). The accommodation offer, the room, that was used as stimulus selected was very neutral and did not show gender-related features or untidiness. It could be that this would already have influenced one's emotional state before it was measured with the PAD constructs. When the room did not satisfy personal preferences, the emotional state could be more negative, resulting in an overall lower purchase intention without being influenced by the background colour. Further research should therefore also include the emotional state of the participant before conducting the study.

The findings in this study contribute to the existing literature about both purchase intention in an online environment and emotions. It was found that pleasure influences the relationship between the background colour and booking intention, indicating that a light red background results in greater pleasure and thus more purchase intention. Web store owners should keep this information in mind when designing the colour scheme of the web store. A lighter high value red could be a good option to use on the web store, since this results in a higher level of pleasure in the consumer, which in turn results in a higher purchase intention. For a dark background, no interaction effects were found, and it was also identified that a dark background (low value) results in the lowest booking intention. Therefore, its use would not be recommended in the colour scheme of web stores. This study suggests that web stores do not need to alter the colour scheme for restricted and indulgent cultures, since no difference between these cultures was found. A global web store with an overall uniform colour scheme across both cultures will suffice.

\section{Acknowledgements}

The authors would like to thank the anonymous reviewers for their constructive comments throughout the review process. Their suggestions significantly improved the quality of this study.

\section{References}

Basaran, U., \& Buyukyilmaz, O. (2015). The effects of utilitarian and hedonic values on young consumers' satisfaction and behavioral intentions. Eurasian Journal of Business and Economics, 8(16), 1-18. https://doi.org/10.17015/ejbe.2015.016.01

Broeder, P., \& Scherp, E. (2017). Colour preference of online consumers: A cross-cultural perspective. Marketing from Information to Decision Journal, 1(1), 1-11. https://doi.org/10.2478/midj-2018-0001

Broeder, P., \& Snijder, H. (2019). Colour in online advertising: Going for trust, which blue is a must? Marketing from Information to Decision Journal, 2(1), 5-15. https://doi.org/10.2478/midj-2019-0001

Bui, D. T. (2015). Consumer acceptance of functional foods in ho chi Minh City. Eurasian Journal of Business and Economics, 8(16), 19-34. https://doi.org/10.17015/ejbe.2015.016.02

Cavanaugh, L. A. (2014). Because I (don't) deserve it: How relationship reminders and deservingness influence consumer indulgence. Journal of Marketing Research, 51(2), 218-232. https://doi.org/10.1509/jmr.12.0133 
Clarke, T., \& Costall, A. (2008). The emotional connotations of colour: A qualitative investigation. Colour Research \& Application, 33(5), 406-410. https://doi.org/10.1002/col.20435

Clee, M. A., \& Wicklund, R. A. (1980). Consumer behavior and psychological reactance. Journal of Consumer Research, 6(4), 389-405. https://doi.org/10.1086/208782

Eroglu, S. A., Machleit, K. A., \& Davis, L. M. (2003). Empirical testing of a model of online store atmospherics and shopper responses. Psychology \& Marketing, 20(2), 139-150. https://doi.org/10.1002/mar.10064

Francis, J. E. (2009). Category-specific RECIPEs for internet retailing quality. Journal of Services Marketing, 23(7), 450-461. https://doi.org/10.1108/08876040910995248

Fraser, T., \& Banks, A. (2004). Designer's colour manual: The complete guide to colour theory and application. San Francisco: Chronicle Books.

Gorn, G. J., Chattopadhyay, A., Tracy, Y., \& Dahl, D. W. (1997). Effects of colour as an executional cue in advertising: They're in the shade. Management Science, 43(10), 1387-1400. https://doi.org/10.1287/mnsc.43.10.1387

Gorn, G. J., Chattopadhyay, A., Sengupta, J., \& Tripathi, S. (2004). Waiting for the web: How screen colour affects time perception. Journal of Marketing Research, 41(2), 215-225. https://doi.org/10.1509/jmkr.41.2.215.28668

Hall, R. H., \& Hanna, P. (2004). The impact of web page text-background colour combinations on readability, retention, aesthetics and behavioural intention. Behaviour \& Information Technology, 23(3), 183-195. https://doi.org/10.1080/01449290410001669932

Hayes, A. F. (2018). Introduction to mediation, moderation, and conditional process analysis: $A$ regression-based approach. New York: Guilford Publications.

Hsieh, Y. C., Chiu, H. C., Tang, Y. C., \& Lee, M. (2018). Do colours change realities in online shopping? Journal of Interactive Marketing, 41(1), 14-27. https://doi.org/10.1016/j.intmar.2017.08.001

Koo, D. M., \& Ju, S. H. (2010). The interactional effects of atmospherics and perceptual curiosity on emotions and online shopping intention. Computers in Human Behaviour, 26(3), 377-388. https://doi.org/10.1016/j.chb.2009.11.009

Lee, Y. J., \& Lee, J. (2006). The development of an emotion model based on colour combinations. International Journal of Consumer Studies, 30(2), 122-136. https://doi.org/10.1111/j.1470-6431.2005.00457

Lu, Q. S., Pattnaik, C., Xiao, J., \& Voola, R. (2017). Cross-national variation in consumers' retail channel selection in a multichannel environment: Evidence from Asia-Pacific countries. Journal of Business Research, 86(1), 321-332. https://doi.org/10.1016/j.jbusres.2017.09.027

Mathwick, C., Malhotra, N., \& Rigdon, E. (2001). Experiential value: Conceptualization, measurement and application in the catalog and Internet shopping environment. Journal of Retailing, 77(1), 39-56. https://doi.org/10.1016/\$0022-4359(00)00045-2

Mazaheri, E., Richard, M. O., \& Laroche, M. (2011). Online consumer behaviour: Comparing Canadian and Chinese website visitors. Journal of Business Research, 64(9), 958-965. https://doi.org/10.1016/j.jbusres.2010.11.018

Mehrabian, A., \& Russell, J. A. (1974). An approach to environmental psychology. Cambridge: the MIT Press. 
Meier, B. P., Robinson, M. D., \& Clore, G. L. (2004). Why good guys wear white: Automatic inferences about stimulus valence based on brightness. Psychological Science, 15(2), 82-87. https://doi.org/10.1111/j.0963-7214.2004.01502002.x

Morton, J. (2009). Who owns hues. Colour Matters. Retrieved from: http://www.colormatters.com/color-and-marketing/color-and-trademark

Mummalaneni, V. (2005). An empirical investigation of website characteristics, consumer emotional states and on-line shopping behaviours. Journal of Business Research, 58(4), 526532. https://doi.org/10.1016/S0148-2963(03)00143-7

Okada, E. M. (2005). Justification effects on consumer choice of hedonic and utilitarian goods. Journal of Marketing Research, 42(1), 43-53. https://doi.org/10.1509/jmkr.42.1.43.56889

Overby, J. W., \& Lee, E. J. (2006). The effects of utilitarian and hedonic online shopping value on consumer preference and intentions. Journal of Business Research, 59(10), 1160-1166. https://doi.org/10.1016/j.jbusres.2006.03.008

Pelet, J. E. (2015). Investigating the importance of website colour contrast in E- and MCommerce. In Khosrow-Pour, M. (Ed.), Encyclopedia of Information Science and Technology, Third Edition (pp. 2329-2338). Hershey, PA: IGI Global. https://doi.org/10.4018/978-1-46665888-2.ch226

Pelet, J. E., \& Papadopoulou, P. (2012). The effect of colours of e-commerce websites on consumer mood, memorization and buying intention. European Journal of Information Systems, 21(4), 438-467. https://doi.org/10.1057/ejis.2012.17

Poels, K., \& Dewitte, S. (2008). Getting a line on print ads: Pleasure and arousal reactions reveal an implicit advertising mechanism. Journal of Advertising, 37(4), 63-74. https://doi.org/10.2753/JOA0091-3367370405

Sharma, P., Sivakumaran, B., \& Marshall, R. (2011). Deliberate self-indulgence versus involuntary loss of self-control: toward a robust cross-cultural consumer impulsiveness scale. Journal of International Consumer Marketing, 23, 229-245. https://doi.org/10.1080/08961530.2011.578060

Sherman, G. D., \& Clore, G. L. (2009). The colour of sin: White and black are perceptual symbols of moral purity and pollution. Psychological Science, 20(8), 1019-1025. https://doi.org/10.1111/j.1467-9280.2009.02403.x

Singh, S. (2006). Impact of colour on marketing. Management Decision, 44(6), 783-789. https://doi.org/10.1108/00251740610673332

Triandis, H. C. \& Gelfand, M. J. (1998). Converging measurement of horizontal and vertical individualism and collectivism. Journal of Personality and Social Psychology, 74(1), 118-128.

Van der Westhuizen, D., \& Solms, M. (2015). Social dominance and the affective neuroscience personality scales. Consciousness and Cognition, 33(1), 90-111. https://doi.org/10.1016/j.concog.2014.12.005

Vieira, V. A. (2013). Stimuli-Organism-Response Framework: A meta-analytic review in the store environment. Journal of Business Research, 66(9), 1420-1426. https://doi.org/10.1016/j.jbusres.2012.05.009

Weathers, D., Subhash S., \& Wood, S. L. (2007). Effects of online communication practices on consumer perceptions of performance uncertainty for search and experience goods. Journal of Retailing, 83(4), 393-401. https://doi.org/10.1016/i.jretai.2007.03.009 


\section{Appendix}

\begin{tabular}{cl}
\hline Scale for booking intention & I would like to book this room \\
\hline Scale for emotion & \\
\hline Pleasure & Unhappy - Happy \\
& Annoyed - Pleased \\
& Unsatisfied - Satisfied \\
& Despairing - Hopeful \\
\hline Arousal & Relaxed - Stimulated \\
& Calm - Excited \\
& Sleepy - Wide-awake \\
& Unaroused - Aroused \\
\hline Dominance & Cared for - In control \\
& Controlled - Controlling \\
& Submissive - Dominant \\
Influenced - Influential
\end{tabular}

